Ambient Science, 2020: Vol. 07(Sp1); 50-55

DOI:10.21276/ambi.2020.07.sp1.ga02

\title{
Analyzing the Texts of Summit Book Written By the Mountaineers who Climbed to the Mount Kackar \\ Abstract
}

\section{Burak Kural A, Fatih Bektaș}

Trabzon University, Faculty of Sport Sciences, Trabzon, Turkey

Study Area: Trabzon, Turkey

Coordinates: $41^{\circ} \mathrm{oo}^{\prime} 18 ? \mathrm{~N} 39^{\circ} 43^{\prime} 21$ ? E

Key words: Mountaineering, Climbing, Summit Notebook, Kaçkar Mountain
In this article, document examination method of qualitative research methods was used. The data were obtained from the texts written in the summit book of Kackar mountain in 2017 during the summer climbing period of 2014. The content analysis method was used in the analysis of the data. Content analysis forms consist of two parts. In the first part, it includes information about gender, nationality, participation and climbing route, in the second part, it includes the climbers' shares about the state of being at the peak. We analysed total numbers of persons climbed to Kackar mountain in summer climbing period. Further, gender and citizen wise analysis was done. Further, individual or club wise climbers participated were also analysed. Interestingly, $28.5 \%$ of the total climbers preferred the northern classical route, $69.1 \%$ preferred the south classical route and $2.2 \%$ preferred the glacier route. According to the results of the survey conducted on 240 chapters in the summit book, it was determined that when they were at the top, the climbers had shared emotional, success, struggle, technical knowledge and political contents. As a result, it was found that the numbers of male climbers are more than female climbers and also the peak climbs were concentrated on the southern classical route. However, it was determined that emotional content remains at the forefront of the texts in the summit book.

wide mountain range that consists of four parts (Verçenik Mountains, Kaçkar-Kavrun Mountain, Bulut Mountains and Altiparmak Mountains). (Findik, 20o1; ÜIker, 1992). This mountain range has more than 30 mountain masses of 3000 meters and above. One of these mountain masses is Kaçkar Mountain. Kackar mountain is 3937 meters high, and it is the 4 th biggest mountain in Turkey. The northern slopes of the Kaçkar Mountain are in Rize and the southern slopes are in Artvin. (Bektas, 2010).

There are climbing routes with different difficulties including mountain hiking, technical and traditional climbing, glacier climbing to reach the summit of Kaçkar Mountain. The easiest of these routes is the South route, which basically requires mountain hiking. It is a route that has low technical difficulty and is often used by more commercial walking tours. The altitude of this route, which has an alpine degree of $\mathrm{F}$ (easy), is approximately 1250 meters from the "Dilber düzü" to the summit. Climbing to Kaçkar Mountain from this climbing route can be achieved 
by anyone in good physical condition. The easiest route for those approaching the Kaçkar Mountain from the north is the northern classic (North-East ridge) route. Although the route includes steep rocky stages, the route is technically quite easy but generally long and very rotten. The Alpine degree of the route can be defined as PD- (somewhat difficult) (Findik, 2015). There are two different glacial routes to climb to the summit of Kaçkar Mountain. These are the northwest glacier route (big glacier) and northeast glacier route (small glacier) routes. (URL-1, 2019). The Kaçkar north-west glacial route can be a dangerous and challenging route, especially due to stone fall in the advanced season. For this reason, it is much safer to climb at the beginning of the season. Some technical equipment is needed to climb to the great glacier which has alpine grade PD + (somewhat difficult) (Findik, 2015).

The northern-facing slopes of Kaçkar Mountain have humid and temperate sea climate. On the south-facing slopes, there is an arid and completely continental climate opposite to that of the north. There are sunny and clear days in every month in Kaçkar Mountain. However, it is seen that the ideal weather is mostly in July and August and at the beginning of September (Findik, 2015). When the mountaineering climbing period is considered, it is seen that the summer climbing period of Kaçkar Mountain is between 21 March and 21 December (TDF, 2018).

Mountaineering is defined as "reaching the top of the mountains or climbing to a defined point" (UIAA, 2015). Mountaineering is a recreational product that can be purchased or produced by the individual. The reasons that direct the individual to mountaineer in recreational terms arise from the positive and effective benefits provided by the individual from participating in these activities (Ercan \& Sar, 2004; Kaplan, 2012). Because mountaineers desire to have fun, to be spiritually well, to be happy and to gain social communication while heading towards this sport (Ekici et al., 2011).

There is a notebook at the summit, the last point of the mountains. This book is located in the most summits of the mountains in Turkey. In the summit book; there are texts in which they share impressions about the mountain, information about the route they climbed, experiences and emotions. In this direction, the aim of the research is to analyze the content of the texts about the route information, experiences and feelings written in the summit notebook by those who climbed Kaçkar Mountain (3937m).

\section{Methodology:}

Our effort, which was carried out to examine the reflection of the texts about the posts written in the summit notebook by those who climbed Kaçkar Mountain (3937m), was handled on the basis of document analysis. The main purpose of document analysis; is the analysis of written documents, scientific researches, project reports, official and historical documents about the situation, facts and facts aimed to be investigated (Atkinson \& Coffey, 2004).

The required data were obtained from the texts written in the summit notebook of Kaçkar Mountain in 2017. The content analysis method was used in analyzing the data collected through the document. The following stages were followed in these analyzes: (i) Creating raw data texts by transferring the data to the computer environment and preparing these texts for data analysis; (ii) Coding of data in line with the answers given by the teachers; (iii) Creating themes from the accessed codes; (iv) Arrangement of codes and themes; (v) Presentation and interpretation of the findings (Creswell, 2007; Strauss \& Corbin, 1990; Yildirim \& Simsek, 2005). While document analysis, data are organized into themes, categories and case examples through content analysis. The obtained qualitative assessment data can be presented alone or together with quantitative data (Labuschagne, 2003). During this whole process, validity and reliability studies were carried out.

Achieving validity in content analysis depends on the harmony between the aims and means of the research. In order to ensure this harmony, the validity has been increased by detailing the coding processes. Reliability is related to the clearly defined and understandable sections of the content analysis (Gökçe, 2006). For this purpose, the sections to be examined are explained. Internal reliability of the research has been tested with reproducibility (reproducibility or inter-rater reliability), which is also referred to as inter-coder reliability. Inter-coder reliability is expressed as the result of the classification applied to the same text by more than one coder, giving the same results. (Petch, 2004). For reliability, the assistance of another academist from communication faculty was consulted, and the inter-coder reliability coefficient was found as 0.83 . In addition, in order to verify the results obtained during the data analysis process, the help of two academicians who are experts in qualitative research were requested, and their opinions about the codes and themes were obtained and the necessary arrangements were made in this direction. Findings were presented without any comments, and direct quotations were frequently included. In order to confirm the codes and themes, opinions were obtained from two academicians who are experts in their fields.

\section{Our Analysis:}

As per the analysis of the texts about the climbing written by the individuals who climbed to Kaçkar Mountain during the summer climbing period (21 Mar.-21 Dec.); the information about the route they climbed, gender, nationality, participation and being at the summit, and sharing are presented below.

Figure-1 determined that there are 785 climbers climbed to Kaçkar Mountain and shared his/her feelings to the summit notebook. 20.2\% were female (159) and 79.8\% were male (626) climbers. The most climbs on Kaçkar 


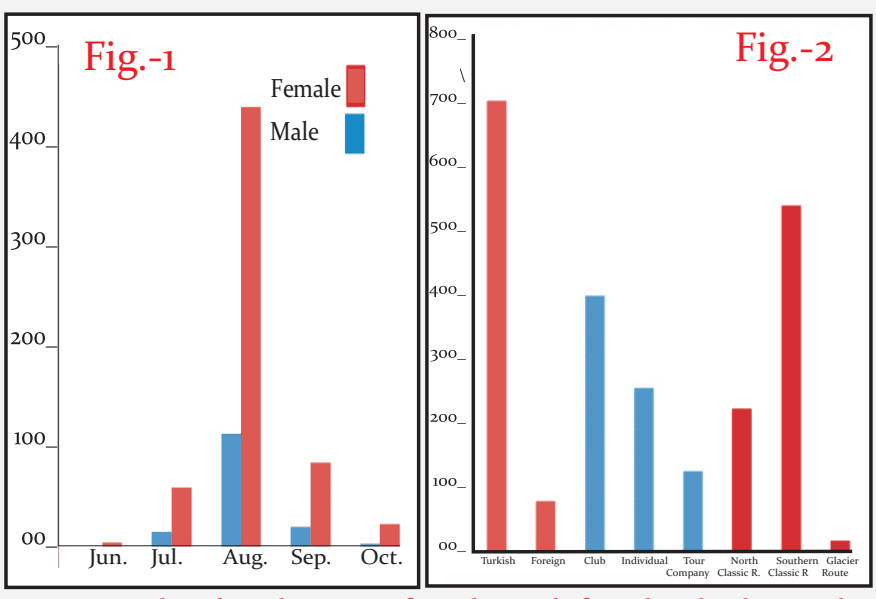

Figure-1: The distribution of male and female climbers who climbed to Kaçkar Mountain by months.

Figure-2: Distribution according to the route climbed, nationality and participation status

\begin{tabular}{|c|c|}
\hline \multirow{3}{*}{$\begin{array}{l}0 \\
0 \\
\text { ๓ }\end{array}$} & Emotional Content \\
\hline & Stating Success \\
\hline & Technical Content \\
\hline & Referring \\
\hline & Political Content \\
\hline$\Xi$ & Naturalism \\
\hline & Negative Content \\
\hline
\end{tabular}

Mountain was August (71.8\%) and the month with the least climb was June (o.8\%). 57.1\% of the total climbers were men (448) and $14.7 \%$ were women (116) in August.

The distribution of the route climbed, nationality and participation status in the study is given in Figure-2; $90.1 \%(707)$ of the total Figure-3: Summary of the climbers were Turkish and analysis extracted from the $9.9 \% \quad(78)$ were foreign texts in the summit book. nationals. Similarly, 51.1\% (401) were with their clubs, $32.7 \%$ (257) were individual and $16.2 \%$ (127) with the tour company. It was observed that $28.5 \%$ (224) of the total summits preferred the northern classical route, $69.1 \%$ (543) preferred the southern classical route and $2.2 \%(18)$ preferred the glacier route.

The summary of the findings related to the codes and themes obtained as a result of the analysis of the posts that they wrote in the summit notebook climbing the Kaçkar Mountain is presented in Fig.-3.

When Fig.-3 was analysed under 7 different themes and 14 codes as a result of the analysis of the texts written in the summit notebook by the climbers. The first of these was the "emotional content" theme; it appeared to emerge in the codes of being happy, longing, finding peace and being thankful. The theme of dedicating, sending greetings and thanking was covered under the theme of "sending". Achieving and struggling "stating success"; regret and suffering are discussed under the themes of "negative content". It was seen that technical knowledge emerges in the theme of "technical content", political message in the theme of "political content", admiring the scenery under the theme of "naturalism".
Table-1: Categories, codes and frequencies that emerged according to the analysis of the texts in the summit book.

\begin{tabular}{|c|c|c|c|}
\hline \multicolumn{4}{|c|}{ Categories } \\
\hline Codes & f & $\%$ & Statement \\
\hline \multicolumn{4}{|c|}{ Emotional Content } \\
\hline Enjoy & 28 & $15 \cdot 56$ & $\begin{array}{l}\text {..I am very happy that every } \\
\text { mountaineer should taste this feeling. }\end{array}$ \\
\hline $\begin{array}{l}\text { Thanks } \\
\text { giving }\end{array}$ & 11 & 6.11 & .. We thank and praise at Kaçkar summit. \\
\hline Missing & 8 & 4,44 & $\begin{array}{l}\text { We reached the Kaçkar summit, which } \\
\text { I have been longing for years. }\end{array}$ \\
\hline $\begin{array}{l}\text { Finding } \\
\text { Peace }\end{array}$ & 4 & 2,22 & $\begin{array}{l}\text {... I find peace here. I would recommend } \\
\text { it to everyone.... }\end{array}$ \\
\hline
\end{tabular}

\section{Stating Success}

Achieving $6 \quad 3,33 \quad$...I am very happy to have achieved this difficult summit.

Struggling $12 \quad 6,67$...Climbing to Kaçkar Summit is a difficult, arduous process that requires determination and perseverance. I was so scared I gave up many times but now I'm here.

Referring

Dedication 37 20,56 ...I present this summit to my endless love Derya.

Sending $\quad 17 \quad 9,44 \quad$...Greetings to my dear wife Seher and greetings my little baby from Kaçkar summit.

Thanking $13 \quad 7,22 \quad$...Thank you soooo much to all my team who made me experience this.

Technical Content

Technical $5 \quad 2,78$...Camping place: “Öküz Yatagi” Route: Information Classic (North rock stage) Duration: 07.0o Departure from the glacier , 11.45 arrival at the summit.

\section{Political Content}

Political $\quad 5 \quad 2,78 \quad$...Damn Israel, Syria, and their tools, Message ISIS, who oppress Muslims in the world.

\section{Naturalism}

Admiring $13 \quad 7,22 \quad$...A beautiful view, lake, glacier, what a the Scenery beautiful thing to live.

Negative Content

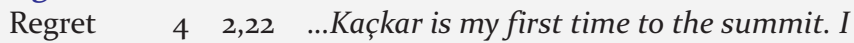

Feeling $\quad 3 \quad 1,67 \quad$...I'm dizzy. I feel sick.

pain

As seen in Table 1, when climbers climbed to the summit under the theme of referring, it was observed that they mostly shared "dedication $(\mathrm{f}=37)$," sending greetings " $(\mathrm{f}=$ $17)$ and" thanking " $(f=13)$. Under the emotional content theme, it was determined that they shared mostly happiness $(f=28)$, thankfulness $(f=11)$, longing $(f=8)$ and feeling peace $(f=4)$. There are sample of texts below in which the values of "dedication" and "emotional content" are handled in the texts of the summit book.

...I present this summit to my endless love Derya.

...I present this summit to my late father E.BANBUL.

...I am very happy that every mountaineer should taste this 
feeling.

... The pleasure of sharing the happiness of being on the summit of Kaçkar with my friends.)

Under the theme of stating success it was observed that they shared struggling $(f=12)$ and achieving $(f=6)$; under the negative content theme, it was observed that they shared regret $(f=4)$ and suffering $(f=3)$. Here are sample texts below that deal with these themes.

...Climbing to Kaçkar Summit is a difficult, arduous process that requires determination and perseverance. I was so scared I gave up many times but now I'm here.

...Kaçkar is my first time to the summit. I have a headache. I will not come again.

...Kaçkar is my first time to the summit. I have a headache. I will not come again.

...I swear I won't come again.

...I'm dizzy. Ifeel sick..

...I am very happy to have achieved this difficult summit.

It was determined that they shared "technical knowledge" ( $\mathrm{f}=5$ ) under the theme of Technical Content, "political message" $(\mathrm{f}=5)$ under the theme of political content, and "admiring the view" $(\mathrm{f}=13$ ) under the theme of naturalism. Here are sample texts below that deal with these themes.

...Camping place: “Öküz Yatagi” Route: Classic (North rock stage) Duration: 07.00 Departure from the glacier , 11.45 arrival at the summit.

...Damn Israel, Syria, and their tools, ISIS, who oppress Muslims in the world.

...A beautiful view, lake, glacier, what a beautiful thing to live... ...Wow! What a beauty again!

\section{Discussion:}

One of the extreme sports that has attracted people's attention as an alternative to popular sports culture in recent years is mountain climbing. Mountaineering sport; may attract a relatively limited number of people due to its distance, physical difficulty, requiring a certain economic strength and technical knowledge, and difficulties in adapting to living in nature conditions (Ülker, 1992). In our study, it was determined that the number of female climbers (159) who climbed to the summit of Kaçkar Mountain was less than male climbers (626). Ekici et al., (2011) tried to examine the differences of individuals engaged in mountaineering according to gender and groups, it was found that $68.7 \%$ of the participants were male. Kalkan (2012) found that people who participated in mountaineering and rock climbing in and around Antalya were mostly men. In both studies, it is observed that mostly men prefer mountaineering. Although there has been a convergence in participation rates between men and women in recent years, the difference is still in favor of men. Women have more limited opportunities in this regard due to their roles (such as mother, wife, business life, etc.) (Ardahan \& Lapa, 2011). For these reasons, it is seen that the rate of engaging in tough mountaineering is lower than men. With the creation of new opportunities for women, making legal regulations, and the impact of women's movements, there has been an increase in women's participation in sports. However, it is observed that participation is less in sports that require physical and psychological endurance (Ardahan \& Lapa, 2011). Mountaineering is one of these sports. These results in the field article correspond with the results of our research. It was observed that those who climbed to Kaçkar Mountain climbed mostly in August (71.8) when compared to the months during the summer climbing period (21 March-21 December). Findik (2003), emphasized the most ideal climbing month of the Kaçkar Mountain is August.

It has been determined that the number of foreign climbers (9.9\%) who climbed to Kaçkar Mountain is very low as against the number of Turkish climbers (90.1\%).It was also determined that male foreign climbers climbed more than female foreign climbers. Nowadays mountaineering; by providing services such as transportation, accommodation, hospitality and guidance to mountaineers, it has become a touristic and recreational activity and has turned into a tourism activity done by millions of people all over the world (Ceylan \& Demirkaya, 2009; Çetinkaya, 2014). Participants have different perceptions about mountaineering tourism. Factors such as push and pull factors, lifestyle and personality traits affect these perceptions (Hendis, 2013). Beedie \& Hudson (2003) stated that three main factors facilitate the formation of adventure tourism and thus affect mountaineering. These factors are; the control of experts in carrying out activities, incentive tools such as promotional brochures and technology applied in the adventure environment, and these come together to form a buffer zone for this tourism activity experience. According to Pomfret (2011), many factors such as equipment developments, technology support systems, improved tourism infrastructure, easier accessibility and reduced risk levels also facilitate the increase of mountaineering. Based on the results of the research, it can be said that these and similar applications in Kaçkar Mountain can increase mountain tourism in this region.

The number of people who climbed the Kaçkar mountain with the club during this summer climbing season was more than the total number of people climbing individually and with a tour company. It could be said that this situation is closely related to the increase in the number of active climbers in the clubs with the increasing spread of mountaineering sport and the increase in the number of clubs in our country. Somuncu (2004) stated that the change in the economic and social structure in our country from the 1980s has also been reflected in Turkish mountaineering sport. Increasing transportation and communication opportunities contributed to the development of mountaineering. Another factor that is 
effective in the progress of mountaineering is that the mountaineering activities, which are directed by the Mountaineering Federation, mountaineering clubs and universities, and that are carried out solely as sports, provide the spread of mountaineering to the base. We can say that these developments support our research results. There are also hiking and mountaineering tourism companies today who organize numerous activities in Turkey. In recent years, increasing number of foreign tourists prefer Kaçkar Mountain (Karadeniz \& Somuncu, 2003; Somuncu \& Karadeniz, 2004). It was observed that the number of people who climbed to Kaçkar Mountain bya tour company was high. However, it still appears to be not as popular and crowded as the Alps and Himalayas. It is thought that this situation is due to the fact that there is no national, regional and local planning for mountain tourism in Kaçkar Mountain and there is no sustainable tourism management.

It has been determined that the most preferred route is southern classical route. The Classic route or South Route is known as the easiest route. Tourism companies and trekking groups reach the summit using this route (Findik, 2015). It has been determined that the least preferred route is the glacial route. Kaçkar Mountain has 2 glacial routes. These are the Big and Small glacial routes. In this study, it was observed that climbing is made from the great glacier. Climbing from these two glacial routes during the summer period involves serious risks. Stones that constantly fall on the slope of the mountain with melting snow can be fatal (URL-2, 2019). In addition, it can be said that the high level of climbing difficulty of the glacier route and having advanced glacier climbing knowledge affect the glacial route preferences of Kaçkar Mountain. These results in the field article correspond with the results of our research.

As a result of the analysis of the texts in the summit book, it has been determined that when the climbers reach the summit, they dedicate a reference to their loved ones or to someone who has passed away. As a result of the emotional reflections experienced by mountaineers when they reach the summit, it can be said that the values they attach importance to in their lives are more prominent.

As a result of the analysis of the texts in the summit book, it has been determined that the climbers prioritize the emotional content emphasis. The mountaineers stated that the feeling of being on the top made them happier. According to Kalkan (2012), the individuals experience emotional changes as a result of mountaineering. It can be said that this situation overlaps with our study. It was observed that the mountaineers expressed their love for nature at a low rate in their posts in the summit notebook. This result may be due to their more emotional and personality traits when they climb to the top.

Acknowledgments:

We are thankful to the President of Turkey Mountaineering Federation.

\section{References:}

Atkinson, P. \& Coffey, A. (2004): Analysing documentary realities. Qua. Res., 3:77-92.

Ardahan, F. \& Lapa, T.Y. (2011): Outdoor recreation: reasons for cyclists and hikers to engage in extreme sports and their benefits. Int. J. Hum. Sci., 8(1):1327-1341.

Beedie, P. \& Hudson, S. (2003): Emergence of Mountain-based Adventure Tourism. Ann. Tour. Res., 30(3):625-643.

Bektaş, F. (2010): Evaluation of Kaçkar basin trekking routes in terms of sports tourism (Unpublished doctoral thesis). Gazi University, Institute of Educational Sciences., Ankara.

Ceylan, S. \& Demirkaya, H. (2009): A Rural Settlement Developing Due to Winter Tourism: Shepherd Isa Village (Isparta).J. East. Geog., 21: 80-94.

Creswell, J.W. (2007): Qualitative inquiry and research design. Thousand Oaks. Pub. by: Sage Publications, California.

Çetinkaya, G. (2014): Rock Climbing Sport as an Adventure Tourism Activity and the Potential of Antalya-Geyikbayırı. East. Geog. Rev., 31:83-100.

Ekici, S., Çolakoğlu, T. \& Bayraktar, A. (2011): A Research on the Reasons of Mountaineering Sports Individuals Tending to This Sport. Phys. Edu. Sport Sci.J., 5(2).

Ercan, A.A. \& Şar, S. (2004): Stress Sources of Pharmacy Pharmacists in Edremit Körfez Area. Ankara Pharm. Fak. J., 33(4):217-242.

Fındık, T. (2001): Kackar Mountains. Pub. by: Homer bookstore publications, Istanbul, Turkey.

Findik, T. (2015): Kaçkar Verçenik Climbing Guide. Pub. by: Alter publications, Istanbul, Turkey.

Gökçe, O. (2006): Content analysis: Theoretical and practical information. Pub. by: Siyasal publications, Istanbul, Turkey.

Güngör, Y. \& Çiftci, Y. (2017): Potential of Geoparks Kaçkar Mountains National Park, 7oth Geological Congress of Turkey April to to 14. Istanbul, Turkey.

Hendis, M. (2013): Mountaineering Adventures to Africa's High Summits: Why do Norwegian Tourists Travel to Mt. Kilimanjaro in Tanzania and Mt. Margherita in Uganda. (Unpublished master thesis). Sport Sciences Department of Physical Education Norwegian School of Sport Sciences.

International Climbing and Mountaineering Federation[UIAA]. (2015): Mountaineering commission standards for voluntary leaders and instructors. http. Instructors http://www.theuiaa.org/documents/safety/MQL-2015. adresinden from 21.12. accessed in 2019.

Kalkan, A. (2012): Outdoor Recreation, The Reasons of The Individuals Who Do Outdoor Sports to Do These Sports: The Example of Antalya.(Unpublished master thesis), Akdeniz University Institute of Social Sciences, Antalya.

Karadeniz, N. \& Somuncu, M. (2003): Approaches for Preservation of Mountainous Areas in Turkey Case Study: Kaçkar Mountains (Turkey). Quell Avenir Pour les Montagne's Mediterranean's, 17:120-123.

Labuschagne, A. (2003): Qualitative research-airy fairy or fundamental? Qual. Rep., 8(1):100-103.

Pomfret, G. (2011): Package mountaineer tourists holidaying in the 
French Alps: an evaluation of key influences encouraging their participation. Tour. Manag., 32:501-510.

Petch, T. (2004): Content Analysis of Selected Health Information Web Sites, http://www.sfu.ca/act4hlth/pub/ working/contentAnalysis.pdf (from 10.10. accessed in 2019)

Somuncu, M. (2004): The Dilemma in Mountaineering and Mountain Tourism: Economic Benefit and Ecological Cost. J. Geog. Sci., 2(1):1-22.

Somuncu, M. \& Karadeniz, N. (2004): Perceptions of eco-tourism in the mountainous area in Turkey: Aladağlar Example II. International Tourism, Environment and Culture Symposium, Izmir.

Strauss, A. \& Corbin, J. (1990): Basics of qualitative research. Newbury Park. Pub. by: Sage Publications Ltd., California.
Mountaineering Federation of Turkey [TDF]. (2018): Turkey Mountaineering Federation of mountaineering training instruction. accessed on 12.01.2020

URL-1,ttps://tr.wikipedia.org/wiki/KackarDagi. Kaçkar Mountain December 24, 2019.

URL-2, https://www.wikizero.com/tr/ KackarDagi. Kaçkar Mountain. 22 December 2019.

Ülker, İ. (1992): Mountain Tourism. Pub. by: T.C. Ministry of Tourism Publication, Ankara, Turkey.

Yildirim, A. \& Șimșek, A. (2005):Qualitative Research Methods in Social Sciences (5th Ed.). Pub. by: Seçkin Publishing House, Ankara, Turkey.

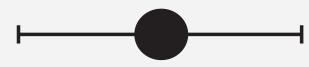

